\title{
Testing Stenting and Flow Diversion Using a Surgical Elastase- Induced Complex Fusiform Aneurysm Model
}

\author{
(D) Rahed, (D)T.E. Darsaut, (DI. Salazkin, (D).-C. Gentric, (D) M. Mazighi, and (D). Raymond
}

\begin{abstract}
BACKGROUND AND PURPOSE: Rabbit elastase-induced saccular aneurysms have been commonly used for preclinical testing of endovascular devices, including flow diverters. However, all tested devices have been shown to be capable of aneurysm occlusion with this model. We aimed to create a more challenging model to test and discriminate among neurovascular devices of varying efficacies.
\end{abstract}

MATERIALS AND METHODS: With a surgical approach that included elastase infusion and balloon dilation, we attempted the creation of complex fusiform aneurysms in 16 rabbits, with standard saccular carotid aneurysms created in 15 other animals. Aneurysms were randomly allocated to one of the following treatments: flow diversion $(n=8)$, high-porosity stent $(n=6)$, double high-porosity stent $(n=5)$, and control $(n=6)$. Angiographic assessment and pathologic analyses were performed at 3 months.

RESULTS: Creation of complex fusiform and standard saccular aneurysms was successful in 12/16 and 13/15 attempts, respectively. All saccular $(n=4)$ or complex fusiform $(n=4)$ aneurysms treated with flow diverters were successfully occluded. Three of 3 saccular compared with $0 / 2$ complex fusiform aneurysms were occluded by double high-porosity stents. One of 3 saccular and $0 / 3$ complex fusiform aneurysms were occluded by a single high-porosity stent. Both aneurysm types shared the same pathologic findings when untreated: The aneurysm wall lacked an elastic layer and smooth muscle cells, while the lumen was lined with neointima of varying thickness. Neointimal coverage of the devices was complete when aneurysms were occluded, while leaks were always associated with aneurysm remnants.

CONCLUSIONS: Challenging fusiform aneurysms can be created in rabbits by using a surgical modification of the elastase method.

ABBREVIATIONS: $\mathrm{FD}=$ flow diverter; $\mathrm{HPS}=$ high-porosity stent

$F$ ow diverters (FDs) are a class of braided stents used to treat intracranial aneurysms. ${ }^{1}$ Compared with high-porosity stents (HPSs) used mainly for stent-assisted coiling of the aneurysmal sac, FDs are lower porosity devices designed to occlude aneurysms

Received June 14, 2016; accepted after revision September 29.

From the Centre Hospitalier de l'Université de Montréal (R.F., I.S., J.R.), Interventional Neuroradiology Research Laboratory, Notre-Dame Hospital, Montreal, Quebec, Canada; Department of Surgery (T.E.D.), Division of Neurosurgery, University of Alberta Hospital, Mackenzie Health Sciences Centre, Edmonton, Alberta, Canada; Department of Radiology (J.-C.G.), Division of Neuroradiology, Centre Hospitalo-Universitaire Cavale Blanche, Brest, France; and Department of Interventional Neuroradiology (M.M.), Fondation Ophtalmologique Adolphe de Rothschild, Paris, France.

This work was supported by a research grant from La Fondation pour la Recherche Médicale to Robert Fahed (grant No. DEA20140630151). FDs, stents, and microcatheters were gifts from MicroVention (Tustin, California).

Please address correspondence to Jean Raymond, MD, Centre Hospitalier de l'Université de Montréal, Notre-Dame Hospital, Department of Radiology, 1560 Sherbrooke East, Pavilion Simard, Suite Z12909, Montreal, Quebec, Canada H2L 4Ml; e-mail: jean.raymond@umontreal.ca

三 Indicates article with supplemental on-line appendix and table.

http://dx.doi.org/10.3174/ajnr.A5018 by repairing the parent vessel. FDs have been shown to be more effective at occluding experimental canine aneurysms compared with high-porosity stents. ${ }^{2}$

A number of experimental aneurysm models are available to test neurovascular devices. ${ }^{3-5}$ The most commonly used model is the rabbit elastase-induced saccular aneurysm model. ${ }^{6-9}$ The model can be created by using endovascular techniques with low morbidity. ${ }^{10}$ However, most studies conducted with this model have shown high occlusion rates irrespective of the device used. ${ }^{6,11-16}$ It remains unclear whether the saccular rabbit elastase model is sufficiently challenging to test flow diversion because complete occlusions have been reported by using non-flow-diverting high-porosity stents. ${ }^{11,12}$ An insufficiently challenging model could result in an overestimation of device efficacy. It may also be incapable of comparing more or less effective flow-diverting devices or may be of limited utility in the exploration of reasons for or mechanisms of treatment failure.

The main objective of the present study was to create and test a rabbit aneurysm model that could offer a more challenging test 

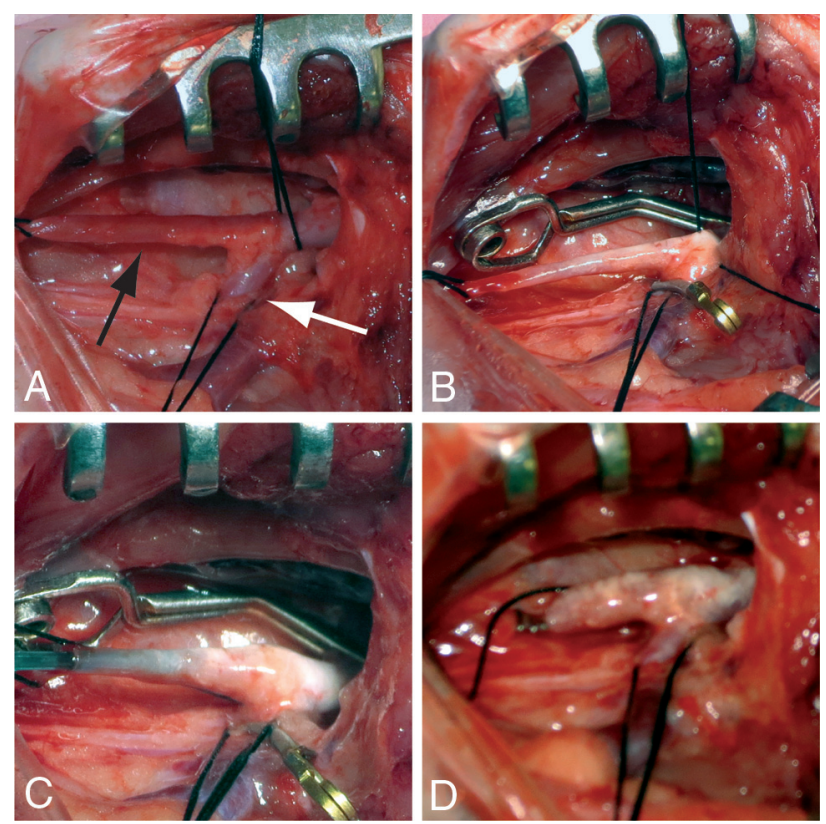

FIG 1. Surgical elastase-induced aneurysm creation. $A$, The right common carotid (black arrow), subclavian (white arrow), and brachiocephalic arteries are encircled with ligatures. $B$, Under temporary clip occlusion, elastase is injected into the lumen and adventitia of the carotid (both models) and subclavian arteries (fusiform model only). C, A $3 \mathrm{~F}$ Fogarty balloon catheter is introduced into the carotid artery for angioplasty. $D$, The distal right carotid artery is occluded, and clips are removed.

of neurovascular devices such as FDs and discriminate among devices of varying efficacies.

\section{MATERIALS AND METHODS}

This article was written in accordance with the Animal Research: Reporting of In Vivo Experiments guidelines. ${ }^{17}$ Protocols for animal experimentation were approved by the Institutional Animal Care Committee in accordance with guidelines of the Canadian Council on Animal Care. Aneurysms were created in New Zealand white rabbits (Oryctolagus cuniculus; mean weight, 3-4 kg). Details of the animal housing and husbandry, anesthesia, and surgical protocols can be found in the On-line Appendix.

\section{Surgical Elastase Aneurysm Creation}

Two types of rabbit aneurysms were created by using elastase: complex fusiform and saccular aneurysms. In 16 rabbits, under general anesthesia, complex fusiform aneurysms were created as follows: A 2- to 3-cm vertical skin incision was made over the right parasternal area. The right carotid artery was located and encircled with ligature (Silk 4-0; Ethicon, Laurel, Maryland), along with the brachiocephalic trunk and the subclavian artery proximal to the vertebral artery (Fig 1A). Strips of latex were placed under isolated arteries to protect the underlying cervical plexus from incubation with elastase. Encircled arteries were temporarily occluded. We then injected approximately $100 \mathrm{IU}$ of porcine elastase $(9.80 \mathrm{U} / \mathrm{mg}$ of protein; $100 \mathrm{U} / \mathrm{mL}$; Worthington Biochemical, Lakewood, New Jersey) into the lumen of the carotid artery, allowing the elastase to enter the subclavian artery. Elastase was also injected into the adventitia of both arteries with a 31-ga needle (Fig 1B). After 20 minutes of elastase incubation, without irrigat- ing the elastase away, a 3F Fogarty balloon catheter (Baxter Healthcare, Irvine, California) was retrogradely introduced into the right carotid artery and progressively inflated at different insertion depths with up to $0.3 \mathrm{~mL}$ of saline for 3 minutes in the right subclavian and carotid arteries, including the ostium (Fig 1C). The balloon catheter was then removed, and the right carotid artery was permanently occluded with clips. Temporary clips were removed, and hemostasis was obtained, covering the arteries with pledgets of collagen sponges when necessary (SURGIFOAM Absorbable Gelatin Sponge; Ethicon) (Fig 1D). The surgical incision was closed by using Vicryl 4-0 for deep layers and Prolene 6-0 (Ethicon) for skin.

In an additional group of 15 rabbits, we created a saccular right carotid artery aneurysm model by using the same surgical procedure as above, but the elastase treatment and balloon dilation were limited to the right carotid artery.

\section{Stents and Flow Diverters}

Stents, flow diverters, and delivery systems were gifts from MicroVention (Tustin, California).

The Low-Profile Visualized Intraluminal Support Device (LVIS; MicroVention) is a self-expanding high-porosity braided stent (not a flow diverter), with an in vitro porosity of $89 \% \pm$ $1.5 \%$ and a pore density of $0.6 \pm 0.5$ full pores $/ \mathrm{mm}^{2}$ (in $3.5-\mathrm{mm}$ straight glass tubes). ${ }^{2}$ Double overlapping LVIS stents (double HPS) result in varying porosities (up to $75.8 \% \pm 1.2 \%$ ) and pore densities (up to $2.3 \pm 2.1$ full pores $/ \mathrm{mm}^{2}$ in optimal in vitro conditions), depending on the extent of overlap of the 2 stents. $^{2}$

The Flow-Redirection Endoluminal Device (FRED; MicroVention) is an FD made of an inner sleeve of low-porosity/highdensity mesh sutured inside an outer LVIS (values measured in 3.5-mm glass tubes). ${ }^{2}$

The diameters and lengths of the LVIS HPSs were $3.0 \times 25$ $\mathrm{mm}, 3.0 \times 41 \mathrm{~mm}$, and $4.5 \times 23 \mathrm{~mm}$, respectively, while those of the FRED FDs were $4.0 \times 23 \mathrm{~mm}$ and $4.5 \times 20 \mathrm{~mm}$.

\section{Endovascular Treatment}

Endovascular treatment was performed 2-3 weeks after aneurysm creation. All animals were administered aspirin $(10 \mathrm{mg} / \mathrm{kg}$ by mouth) and clopidogrel (10 mg/kg by mouth) for 2 days before the procedure and for 1 month thereafter.

Through a right femoral artery cut-down, a $4 \mathrm{~F}$ vascular sheath was introduced, through which a microcatheter (Headway 21 or Headway 27; MicroVention) was advanced into the right brachiocephalic artery. A 4F diagnostic catheter (Glidecath; Terumo, Tokyo, Japan) was used for additional support when necessary.

Aneurysm dimensions and parent arteries were measured by using a Leonardo workstation with syngo software (Siemens, Erlangen, Germany). Assuming that aneurysms were ellipsoid, we calculated aneurysm volumes by using the AngioCalc Web site (http://www.angiocalc.com).

Animals with patent aneurysms $(n=25)$ were randomly allocated treatment by drawing lots: flow diversion $(n=8)$, double overlapping high-porosity stent placement $(n=5)$, single highporosity stent placement $(n=6)$, and control $(n=6)$. 

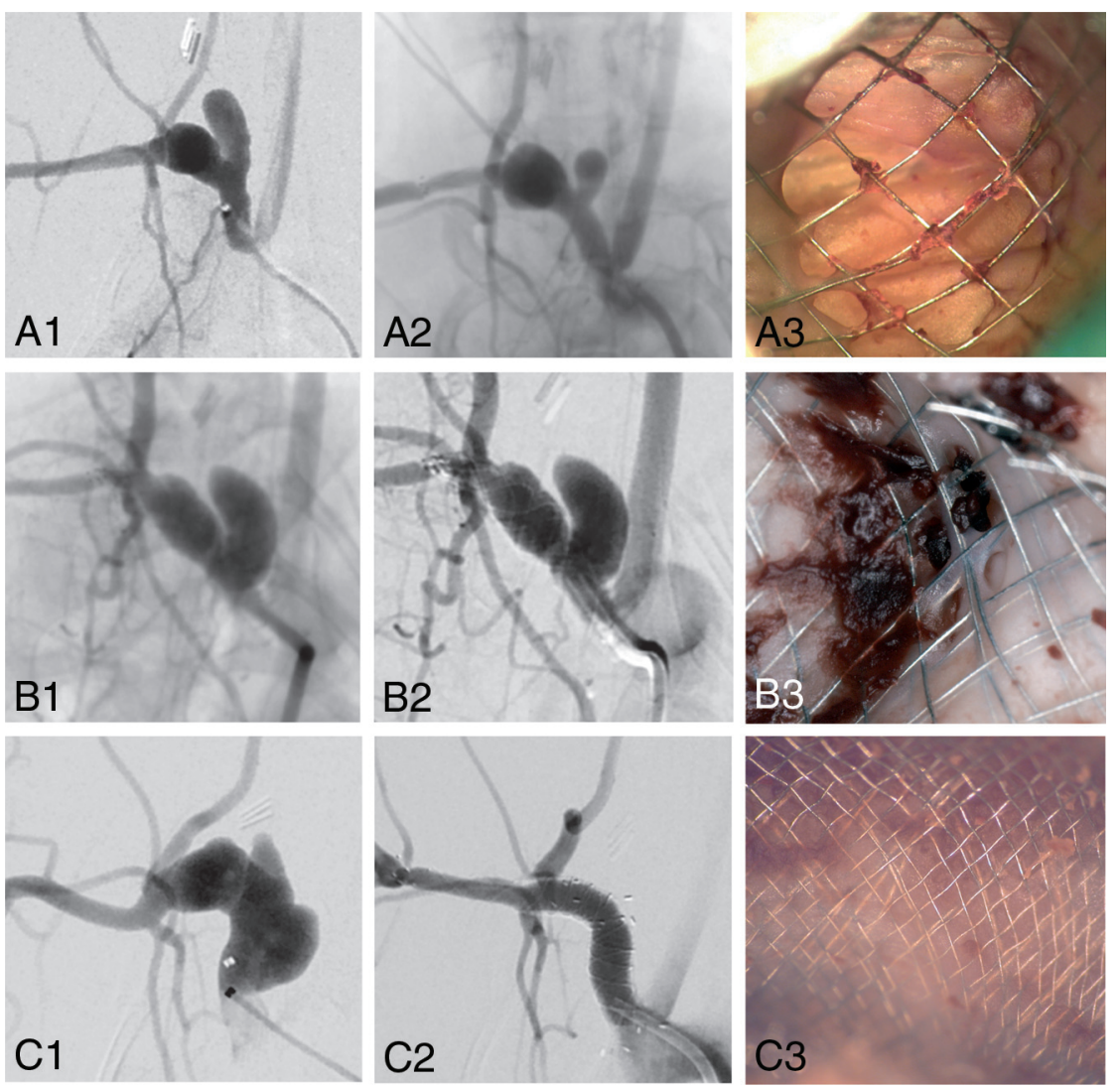

FIG 2. Treatment results (complex fusiform aneurysms). Preimplantation $(A I, B I, C l)$ and 3-month follow-up angiography $(A 2, B 2, C 2)$ and microscopic photography $(A 3, B 3, C 3)$ of complex fusiform aneurysms treated with a single HPS (A), double overlapping HPSs (B), and flow diversion (C) (2 FDs were required). Note angiographic cure after flow diversion, with complete neointimal coverage of the FD. For reference, the diameter of the device wire measures $53 \mu \mathrm{m}$.

\section{Angiography}

Follow-up angiography was performed 3 months after treatment. Through a surgical left femoral artery cut-down, a $4 \mathrm{~F}$ catheter (Glidecath) or a Headway microcatheter was advanced into the aortic arch and the right subclavian artery. The patency of parent vessels and jailed branches was assessed, as well as angiographic aneurysm occlusion according to the grading scales of Kamran et $\mathrm{al}^{18}$ for fusiform and saccular aneurysms. A successful treatment was defined as an angiographic score of 3 or 4 . Angiographic assessment was performed by 2 independent readers (R.F., T.E.D.), with discrepancies resolved in a consensus session.

We hypothesized that devices of decreasing porosity (from a single HPS to a double overlapping HPS to an FD) would increasingly be able to occlude aneurysms and that successful aneurysm occlusion would occur less frequently in the complex fusiform compared with the simple saccular aneurysm model.

\section{Pathology}

After 3-month angiography, animals were euthanized by barbiturate overdose. Aneurysm and arterial constructs were removed en bloc and fixed in formalin for 1 week. Specimens were examined under a microscope and photographed. Aneurysms, arteries, stents, and FDs were cut longitudinally to confirm arterial patency and assess aneurysm occlusion.

We carefully dissected some specimens, removing individual stent wires, to permit pathologic sectioning without metal. In other specimens, aneurysms and representative samples of tissues covering the metallic devices were biopsied under the surgical microscope. Sections were stained with hematoxylin-eosin and Movat pentachrome.

\section{Statistics}

Aneurysm dimensions were compared by using the Student $t$ test. Dichotomized angiographic results (Kamran et $\mathrm{al}^{18}$ grades 3-4 [defined as successful aneurysm treatment] versus grades $0-2$ ) following various treatments were compared by using the Fisher exact test. A $P$ value of .05 was significant.

\section{RESULTS}

Aneurysm Creation and Treatment Aneurysm dimensions are presented in the On-line Table. The mean diameter of the fusiform aneurysms was $54.6 \% \pm$ $27.2 \%$ larger than the upstream normal vessel. Complex fusiform aneurysms were successfully created in 12/16 rabbits. The complex morphology resulted from the combination of a fusiform subclavian aneurysm of varying size, with a "daughter sac" composed of the dilated right carotid artery origin. Two animals had immediate complications (1 vessel rupture during angioplasty; 1 postoperative right limb palsy; both animals were immediately euthanized). In 2 other animals, the parent vessels were occluded at 3 weeks. These 4 animals were excluded from analyses.

The creation of saccular aneurysms was successful in 13/15 rabbits ( 1 vessel rupture during angioplasty; 1 spontaneous aneurysm occlusion at 3 weeks.). These 2 animals were excluded, leaving a total of 25 aneurysms for analyses.

Complex fusiform aneurysms were significantly larger than saccular aneurysms (mean aneurysm volumes, $207.3 \pm 156.9$ $\mathrm{mm}^{3}$, compared with $44.8 \pm 16.7 \mathrm{~mm}^{3}$, respectively; $P=.001$ ).

All endovascular procedures were performed without morbidity or mortality. One animal in the fusiform aneurysm group required 2 telescoping FDs to cross the entire aneurysmal segment.

\section{Angiographic Results}

Angiographic results are presented in the On-line Table and Figs 2 and 3 .

Angiographic results were significantly different among treatments $(P=.0001)$, with flow diversion leading to occlusion more frequently than treatment with a single or double high-porosity stent $(P=.03)$. Overall angiographic results of all treated saccular and fusiform aneurysms were not significantly different $(P=.24)$.

Aneurysms in animals with complex fusiform aneurysms treated with flow diverters were successfully occluded, while those in control animals and those treated with single high-porosity stents remained 

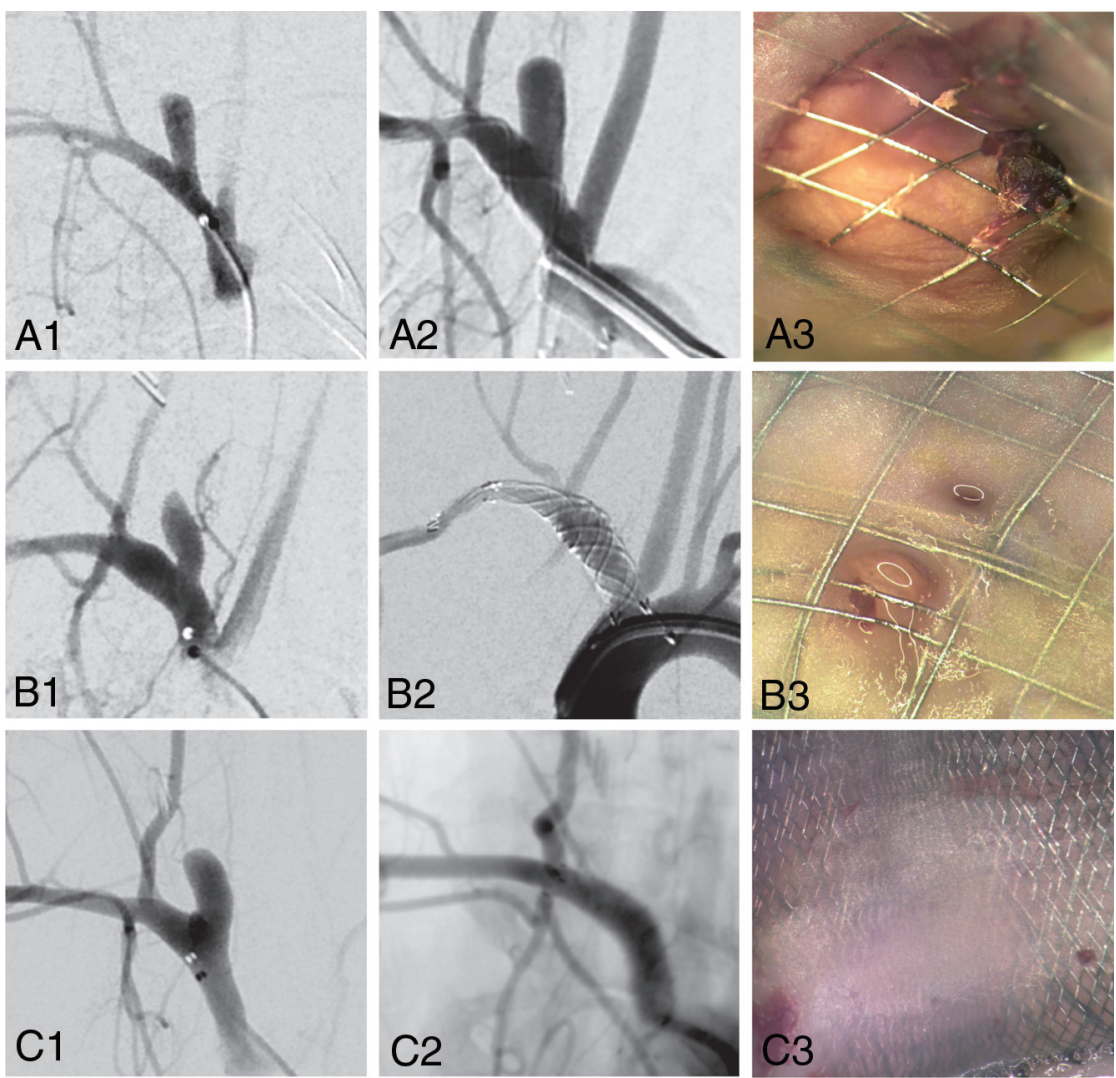

FIG 3. Treatment results (saccular aneurysms). Preimplantation (AI, BI, $C I)$ and 3-month follow-up angiography $(A 2, B 2, C 2)$ and microscopic photography $(A 3, B 3, C 3)$ of saccular aneurysms treated with a single HPS ( $A$ ), double overlapping HPSs $(B)$, and flow diversion (C). Note complete aneurysm occlusion after double HPS placement and flow diversion. For reference, the diameter of the device wire measures $53 \mu \mathrm{m}$.
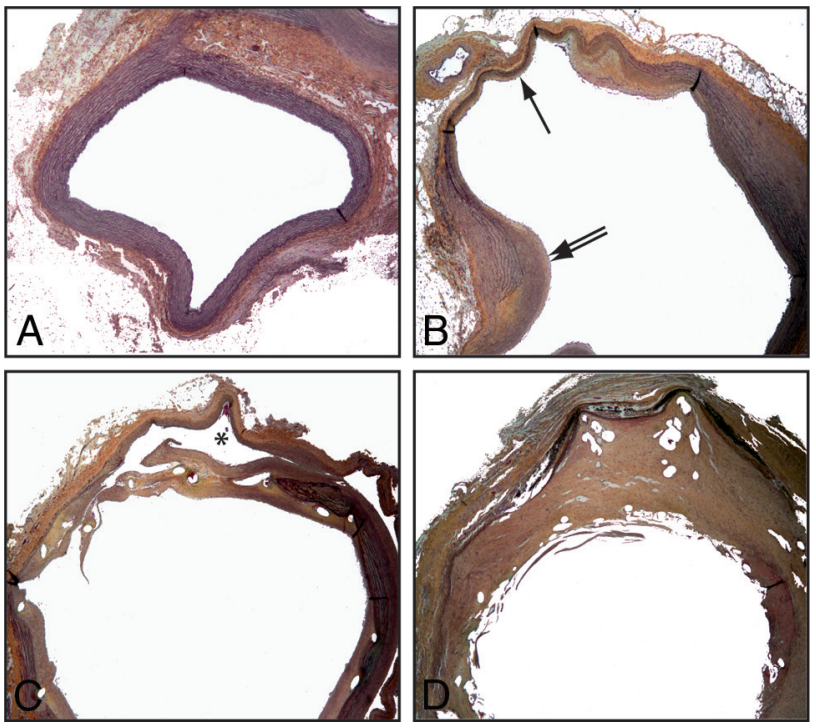

FIG 4. Pathology of untreated, stented, and flow-diverted fusiform aneurysms. The standard saccular model shows a subclavian of normal diameter with a continuous elastic lamina and no neointima formation $(A)$. In comparison, the complex fusiform aneurysm is composed of a dilated thinned wall with a discontinuous media (black arrow) and neointima formation (double arrow). In case of treatment failure with HPS $(C)$, the stent struts were covered with a thin, discontinuous neointima with leaks responsible for the residual aneurysm (partially shown, black asterisk). Successful occlusion of fusiform aneurysms by an FD $(D)$ was associated with thick and complete neointimal coverage of the FD. (Movat staining, original magnification $\times 50$.) patent. Treatment with double overlapping HPSs did not lead to aneurysm occlusion in either of the 2 fusiform aneurysms in which it was attempted. All saccular aneurysms treated with FDs or double overlapping HPSs were occluded. One of 3 saccular aneurysms treated with a single HPS was occluded, while the 2 others remained patent, as did all control aneurysms.

None of the jailed branches were occluded in either model. One animal treated with 2 overlapping HPSs had a distal occlusion of the subclavian artery at 3-month follow-up.

\section{Pathology}

Untreated saccular or fusiform aneurysms shared similar pathologic features 3 months following creation (Figs $4 A$ and $5 A$ ). Compared with the normal arterial wall (Fig $4 B$ ), the aneurysmal wall lacked elastic layers and smooth-muscle cells. The lumen was lined with neointima of varying thickness. Inflammatory cells were infrequent.

In the saccular model, the architecture of the normal artery could be recognized at the neck of the aneurysm (the origin of the right carotid artery as it arises from the brachiocephalic trunk), with reappearance of organized elastic layers (Fig 5B). Some partially organized thrombus could always be found within the fundus of the saccular aneurysm, close to the arterial ligature (Fig 4A). In the fusiform model, the walls of the brachiocephalic trunk and subclavian arteries showed features similar to those of the elastase-treated carotid aneurysms, though the neointimal lining of the aneurysm wall was usually not as thick (Fig $4 A$ ). The wires of all implanted devices closely apposed to the parent vessels at the level of landing zones were covered with neointima of variable thickness. There was no difference in the distribution of neointima covering the proximal or distal ends of the devices. In all cases of incomplete aneurysm occlusion, the neointima covering the stents was incomplete at the level of the aneurysm, leaving large (HPS) (Figs $4 C$ and $5 C$ ) or small gaps (double HPSs) responsible for leaks associated with aneurysm remnants. The wires sometimes seemed bare; at other times, they were covered with neointima, or alternatively with clot. FDs were always completely covered with thick neointima (Figs $4 D$ and 5D).

Aneurysms that were angiographically occluded were sometimes difficult or impossible to recognize at the time of specimen preparation because they had shrunk to the point of being indistinguishable from the other postsurgical fibrous tissues. In some specimens, all that remained was an area of fibrous thickening of the parent vessel now reconstructed by the FD (Fig $4 D$ ). In some others, the saccular (carotid) portion of the aneurysm could be recognized, but the lumen was completely filled with fibrous tissue. There was little inflammation, except for some small areas near the arterial wall where hemosiderin-laden macrophages and giant cells were found (Fig 5D). 


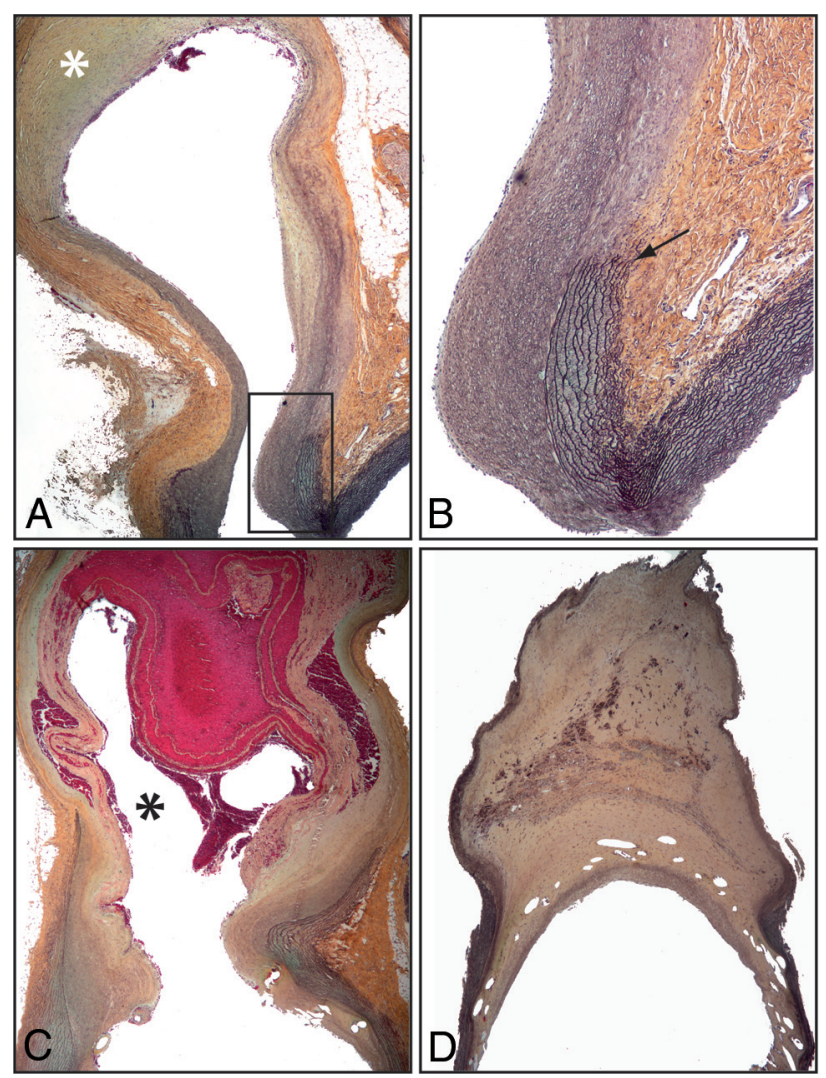

FIG 5. Pathology of untreated, stented, and flow-diverted saccular aneurysms. The saccular aneurysm has an organized thrombus in its dome (white asterisk in $A$ ), with a thin wall with interruption of the elastic lamina at the neck ( $A$, magnified view in $B$, black arrow). In case of treatment failure, the neck was wide open with a persistent aneurysmal cavity (black asterisk), which was only partially filled with unorganized thrombus $(C)$, whereas in case of treatment success, the stent struts were covered with a thick and continuous neointima and the aneurysm cavity was filled with organized thrombus containing areas of hemosiderin $(D)$ (Movat staining, original magnification $\times 50$ ).

\section{DISCUSSION}

The surgical approach we describe allows the creation of a complex fusiform aneurysm model in addition to the standard right carotid saccular model. The new model can be used to provide a challenging test of stents and flow diverters. The model could be used to compare devices of varying efficacy or to explore potential causes of treatment failures.

Elastase-induced rabbit carotid aneurysm models are those most frequently used to test endovascular devices. ${ }^{6}$ Although they are popular, one can question the extent to which tested devices have been challenged, given that virtually all devices have been shown to be successful in occluding aneurysms, including first- ${ }^{13}$ or second- ${ }^{14}$ generation coils, high-porosity stents, ${ }^{11,12}$ and flow diverters. ${ }^{15,16,19}$ A number of technical modifications have been described to overcome this limitation, including attempts to increase the size of aneurysms to make the model more challenging, by adjusting the position of the inflated balloon or the location of carotid ligation. ${ }^{15-18,20}$ We suspect that the main limitation of this type of aneurysm creation is the size of the artery selected for elastase infusion and balloon dilation. Modified surgical approaches have been published as well, but they were limited to elastase incubation and balloon angioplasty of the carotid ar- tery. ${ }^{21-23}$ Other techniques to create fusiform aneurysms with intraluminal injections of elastase $\mathrm{e}^{24,25}$ have reported lesions of smaller dimensions (mean aneurysm width, $3.1 \pm 0.4 \mathrm{~mm}$, compared with $5.1 \pm 1.2 \mathrm{~mm}$ with our technique).

The surgical model we describe allows the operator the freedom to choose which parent vessel will become aneurysmal and thus form a complex aneurysm comprising a saccular lobule originating from a dilated fusiform segment. Attempting to create too large an aneurysm from too small a vessel may lead to vascular rupture or parent vessel occlusion, as we encountered in this exploratory work. Other surgical rabbit models include carotid lateral wall and bifurcation aneurysms made from venous pouches. ${ }^{26-28}$ So far, flow diversion of these rabbit bifurcation aneurysms has not been studied, but FDs were shown to nearly always occlude the surgical sidewall aneurysms. ${ }^{29}$

More complex aneurysm models have been constructed in canines. ${ }^{5,29-31}$ Some models were so challenging that aneurysms remained patent despite implantation of multiple flow diverters. ${ }^{31,32}$ The complex fusiform aneurysms created in this work were larger than the standard rabbit elastase carotid model, but they remain of modest size compared with most canine vein pouch aneurysms. ${ }^{33}$

Rabbit aneurysm models may still have a number of advantages, including simpler logistics, reduced costs, and less technically demanding procedures, while avoiding the difficulties of using dogs for research. Creation of these aneurysms still required surgical expertise. The surgical procedures detailed here may be simpler than those for canine venous pouch aneurysms, ${ }^{5}$ but procedural complications (arterial rupture and brachial plexus injury) nonetheless occurred. The mortality rate (3/31 animals) remained comparable with that of the standard rabbit elastase method. ${ }^{10}$

Although others have shown successful occlusion of elastase aneurysms with HPSs, ${ }^{10,11}$ in this work, HPSs could not reliably occlude either the surgically created saccular or fusiform aneurysms. The surgical modification to the elastase model performed in this work may permit discrimination between endovascular treatments of various efficacies. We were unable to demonstrate statistically significant differences in angiographic results between the 2 surgically created models, which would have required more animals and resources than were available. Nonetheless, the fusiform aneurysms were larger, more complex, and more challenging to treat, and they may offer a more challenging test of endovascular devices than the standard saccular model.

This study has several limitations: The number of animals was small, and follow-up beyond 3 months was not performed. The patency of untreated elastase-induced saccular aneurysms has previously been shown to be durable for up to 5 years. ${ }^{34}$ When creating the saccular, carotid stump aneurysms, modest dilation of the subclavian artery can occur. This has previously been described following the endovascular method of producing carotid stump aneurysms as well. ${ }^{16}$ Fusiform aneurysms were of various sizes. Further refinements in the technique of aneurysm creation may be necessary to reproducibly yield aneurysms of constant dimensions. The method has only been used in a single laboratory. Proof of reproducibility from other centers would be welcome. Experimentally created aneurysms differ from spontaneous intracranial aneurysms, and rabbit biology differs from human biology. Any extrapolation of these results must remain cautious. 


\section{CONCLUSIONS}

Fusiform rabbit aneurysms can be created by using a surgical modification of the elastase method. ${ }^{7}$ This model may offer a more challenging test to compare different endovascular devices.

Disclosures: Robert Fahed_RELATED: Grant: La Fondation pour la Recherche Médicale (grant No. DEA20140630151), Comments: The Fondation pour la Recherche Médicale had no role in this study. Tim E. Darsaut_UNRELATED: Grants/Grants Pending: Canadian Institute of Health Research, Comments: peer-reviewed operating grant for the Collaborative Unruptured Endovascular vs Surgery Study (co-Principal Investigator).* Jean Raymond_UNRELATED: Grants/Grants Pending: Canadian Institute of Health Research for the Collaborative Unruptured Endovascular vs Surgery Study; Unrestricted investigator-led grant for the Does Embolization With Larger Coils Lead to Better Treatment of Aneurysms Trial (DELTA) from DePuy Synthes Johnson \& Johnson Medical Companies*; Other: MicroVention, Comments: stents, flow diverters, and delivery systems were gifts from MicroVention (Tustin, California). * *Money paid to the institution.

\section{REFERENCES}

1. Brinjikji W, Murad MH, Lanzino G, et al. Endovascular treatment of intracranial aneurysms with flow diverters: a meta-analysis. Stroke 2013;44:442-47 CrossRef Medline

2. Darsaut TE, Bing F, Salazkin I, et al. Flow diverters can occlude aneurysms and preserve arterial branches: a new experimental model. AJNR Am J Neuroradiol 2012;33:2004-09 CrossRef Medline

3. Bouzeghrane F, Naggara O, Kallmes DF, et al; International Consortium of Neuroendovascular Centres. In vivo experimental intracranial aneurysm models: a systematic review. AJNR Am J Neuroradiol 2010;31:418-23 CrossRef Medline

4. Naggara O, Darsaut TE, Salazkin I, et al. A new canine carotid artery bifurcation aneurysm model for the evaluation of neurovascular devices. AJNR Am J Neuroradiol 2010;31:967-71 CrossRef Medline

5. Fahed R, Gentric JC, Salazkin I, et al. Flow diversion of bifurcation aneurysms is more effective when the jailed branch is occluded: an experimental study in a novel canine model. J Neurointerv Surg 2016 Apr 11. [Epub ahead of print] CrossRef Medline

6. Fahed R, Raymond J, Ducroux C, et al. Testing flow diversion in animal models: a systematic review. Neuroradiology 2016;58:375-82 CrossRef Medline

7. Cloft HJ, Altes TA, Marx WF, et al. Endovascular creation of an in vivo bifurcation aneurysm model in rabbits. Radiology 1999;213: 223-28 CrossRef Medline

8. Brinjikji W, Ding YH, Kallmes DF, et al. From bench to bedside: utility of the rabbit elastase aneurysm model in preclinical studies of intracranial aneurysm treatment. J Neurointerv Surg 2016;8: 521-25 CrossRef Medline

9. Altes TA, Cloft HJ, Short JG, et al. 1999 ARRS Executive Council Award: creation of saccular aneurysms in the rabbit: a model suitable for testing endovascular devices-American Roentgen Ray Society. AJR Am J Roentgenol 2000;174:349-54 CrossRef Medline

10. Lewis DA, Ding YH, Dai D, et al. Morbidity and mortality associated with creation of elastase-induced saccular aneurysms in a rabbit model. AJNR Am J Neuroradiol 2009;30:91-94 Medline

11. Krings T, Hans FJ, Möller-Hartmann W, et al. Treatment of experimentally induced aneurysms with stents. Neurosurgery 2005;56: 1347-59; discussion 1360 CrossRef Medline

12. Hans FJ, Krings T, Möller-Hartmann W, et al. Endovascular treatment of experimentally induced aneurysms in rabbits using stents: a feasibility study. Neuroradiology 2003;45:430-34 CrossRef Medline

13. Kallmes DF, Helm GA, Hudson SB, et al. Histologic evaluation of platinum coil embolization in an aneurysm model in rabbits. Radiology 1999;213:217-22 CrossRef Medline

14. Ding YH, Dai D, Lewis DA, et al. Angiographic and histologic analysis of experimental aneurysms embolized with platinum coils, Matrix, and HydroCoil. AJNR Am J Neuroradiol 2005;26:1757-63 Medline

15. Kallmes DF, Ding YH, Dai D, et al. A second-generation, endolumi- nal, flow-disrupting device for treatment of saccular aneurysms. AJNR Am J Neuroradiol 2009;30:1153-58 CrossRef Medline

16. Kallmes DF, Ding YH, Dai D, et al. A new endoluminal, flow-disrupting device for treatment of saccular aneurysms. Stroke 2007;38: 2346-52 CrossRef Medline

17. Kilkenny C, Browne W, Cuthill IC, et al; National Centre for the Replacement, Refinement and Reduction of Amimals in Research. Animal research: reporting in vivo-the ARRIVE guidelines. J Cereb Blood Flow Metab 2011;31:991-93 CrossRef Medline

18. Kamran M, Yarnold J, Grunwald IQ, et al. Assessment of angiographic outcomes after flow diversion treatment of intracranial aneurysms: a new grading schema. Neuroradiology 2011;53:501-08 CrossRef Medline

19. Sadasivan C, Cesar L, Seong J, et al. An original flow diversion device for the treatment of intracranial aneurysms: evaluation in the rabbit elastase-induced model. Stroke 2009;40:952-58 CrossRef Medline

20. Ding YH, Dai D, Danielson MA, et al. Control of aneurysm volume by adjusting the position of ligation during creation of elastaseinduced aneurysms: a prospective study. AJNR Am J Neuroradiol 2007;28:857-59 Medline

21. Hoh BL, Rabinov JD, Pryor JC, et al. A modified technique for using elastase to create saccular aneurysms in animals that histologically and hemodynamically resemble aneurysms in human. Acta Neurochir 2004;146:705-11 Medline

22. Wang $\mathrm{K}$, Huang $\mathrm{Q}$, Hong $\mathrm{B}$, et al. Neck injury is critical to elastaseinduced aneurysm model. AJNR Am J Neuroradiol 2009;30:1685-87 CrossRef Medline

23. Ding YH, Danielson MA, Kadirvel R, et al. Modified technique to create morphologically reproducible elastase-induced aneurysms in rabbits. Neuroradiology 2006;48:528-32 CrossRef Medline

24. Alaqeel A, Meek C, Wong J, et al. A novel fusiform aneurysmal model in a rabbit carotid: a combination of pericarotid calcium chloride and elastase incubation. Can J Neurol Sci 2015;42:S12 CrossRef

25. Reinald N, Fournier B, Naveau A, et al. Fusiform aneurysm model in rabbit carotid artery. J Vasc Res 2010;47:61-68 CrossRef Medline

26. Ding YH, Tieu T, Kallmes DF. Experimental testing of a new generation of flow diverters in sidewall aneurysms in rabbits. AJNR Am J Neuroradiol 2015;36:732-36 CrossRef Medline

27. Sherif C, Marbacher S, Erhardt S, et al. Improved microsurgical creation of venous pouch arterial bifurcation aneurysms in rabbits. AJNR Am J Neuroradiol 2011;32:165-66 CrossRef Medline

28. Sherif C, Herbich E, Plasenzotti R, et al. Very large and giant microsurgical bifurcation aneurysms in rabbits: proof of feasibility and comparability using computational fluid dynamics and biomechanical testing. J Neurosci Method 2016;268:7-13 CrossRef Medline

29. Darsaut TE, Bing F, Makoyeva A, et al. Flow diversion of giant curved sidewall and bifurcation experimental aneurysms with verylow-porosity devices. World Neurosurg 2014;82:1120-26 CrossRef Medline

30. Darsaut TE, Bing F, Salazkin I, et al. Flow diverters failing to occlude experimental bifurcation or curved sidewall aneurysms: an in vivo study in canines. J Neurosurg 2012;117:37-44 CrossRef Medline

31. Darsaut TE, Bing F, Salazkin I, et al. Testing flow diverters in giant fusiform aneurysms: a new experimental model can show leaks responsible for failures. AJNR Am J Neuroradiol 2011;32:2175-79 CrossRef Medline

32. Raymond J, Darsaut TE, Makoyeva A, et al. Endovascular treatment with flow diverters may fail to occlude experimental bifurcation aneurysms. Neuroradiology 2013;55:1355-63 CrossRef Medline

33. Gentric JC, Darsaut TE, Makoyeva A, et al. The success of flow diversion in large and giant sidewall aneurysms may depend on the size of the defect in the parent artery. AJNR Am J Neuroradiol 2014;35: 2119-24 CrossRef Medline

34. Ding Y, Dai D, Kadirvel R, et al. Five-year follow-up in elastaseinduced aneurysms in rabbits. AJNR Am J Neuroradiol 2010;31: 1236-39 CrossRef Medline 